
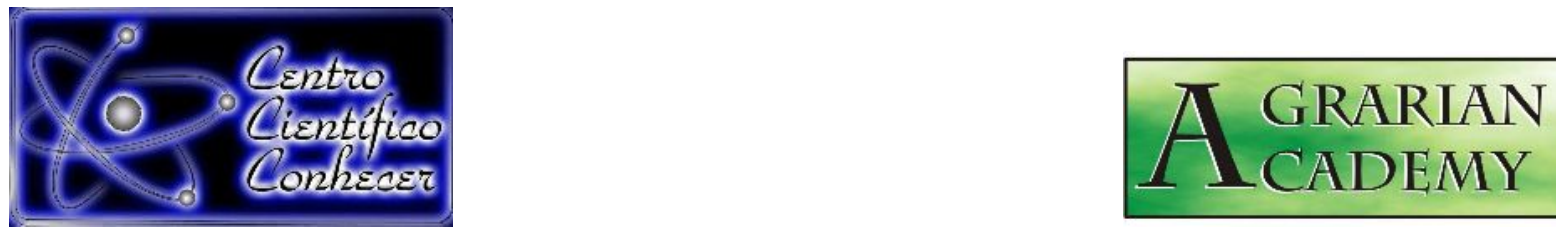

\title{
USO DA TERRA E COBERTURA VEGETAL REMANESCENTE EM ÁREAS DE PRESERVAÇÃO PERMANENTE DOS CURSOS HÍDRICOS DA ZONA URBANA DO MUNICÍPIO DE MIMOSO DO SUL (ES)
}

\footnotetext{
Caio Henrique Ungarato Fiorese ${ }^{1}$, Vinícius Rocha Leite ${ }^{2}$, Tatiana da Silva Lopes ${ }^{3}$

${ }^{1}$ Graduando em Engenharia Ambiental pelo Centro Universitário São Camilo, Cachoeiro de Itapemirim, Espírito Santo, Brasil. (caiofiorese@hotmail.com).

${ }^{2}$ Professor Assistente do curso de Engenharia Ambiental do Centro Universitário São Camilo, Cachoeiro de Itapemirim, Espírito Santo, Brasil.

${ }^{3}$ Professora do colegiado de Ciências Biológicas do Centro Universitário São Camilo, Cachoeiro de Itapemirim, Espírito Santo, Brasil.
}

Recebido em: 02/06/2019 - Aprovado em: 15/06/2019 - Publicado em: 22/07/2019 DOI: 10.18677/Agrarian_Academy_2019a31

\begin{abstract}
RESUMO
O objetivo deste trabalho foi estudar as alterações no uso e cobertura da terra em áreas de preservação permanente (APPs) ciliares no município de Mimoso do Sul (ES) e propor medidas para amenizar os impactos ambientais negativos oriundos

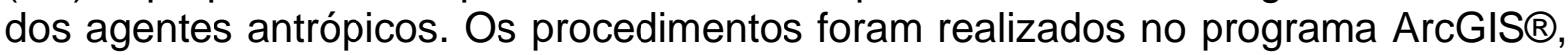
por meio de bases cartográficas estaduais. A área urbana do município de Mimoso do Sul foi delimitada para, posteriormente, por imagens aéreas de alta resolução, fotointerpretar os cursos hídricos que passam pela cidade e delimitar as APPs definidas no Código Florestal. As feições de uso da terra nas APPs foram avaliadas e auxiliaram no mapeamento preciso da cobertura vegetal remanescente. As áreas ocupadas pelas edificações tiveram crescimento expressivo, representando valores significativos (acima de 40\%). A macega representou quase $20 \%$ no córrego Santa Marta, o que pode evidenciar um abandono quanto ao uso das terras. A vegetação arbórea nas APPs é fragmentada com indivíduos isolados e apresentou decréscimo significativo em duas das quatro APPs dos mananciais estudados, com valores ficando entre $32 \%$ e $45 \%$ entre os anos de $2007-2008$ e $30 \%$ e $45 \%$ entre 2012 2015. De modo geral, as APPs dos cursos d'água encontram-se degradadas, devido à elevada presença de edificações e a fragmentação da vegetação ciliar, havendo uma deterioração ao longo do período analisado. Reflorestamento nas APPs e educação ambiental com a população são propostas para melhorar as condições ambientais locais. Monitorar a qualidade e quantidade de água e ampliar a série histórica considerada são ideias para futuros estudos.
\end{abstract}

PALAVRAS-CHAVE: Meio Ambiente; Qualidade de Vida Urbana; Recursos Florestais. 


\title{
LAND USE AND REMAINING VEGETATION COVER IN THE AREAS OF PERMANENT PRESERVATION OF THE WATERCOURSES OF THE URBAN AREA OF THE MUNICIPALITY OF MIMOSO DO SUL (ES)
}

\begin{abstract}
The objective of this work was to study the changes in land use and land cover in permanent preservation areas (PPAs) in the municipality of Mimoso do Sul and propose measures to mitigate the negative environmental impacts of anthropic agents. The procedures were performed in the ArcGIS® program, using state cartographic bases. The urban area of the municipality of Mimoso do Sul was subsequently delimited for later high resolution aerial images, photointerpreting the water courses that pass through the city and delimiting the PPAs defined in the Forest Code. The land use features in the PPAs were evaluated and aided in the accurate mapping of the remaining vegetation cover. The areas occupied by the buildings had significant growth, representing significant values (above 40\%). The macega represented almost $20 \%$ in the Santa Marta stream, which may show an abandonment of land use. The arboreal vegetation in the PPAs is fragmented with isolated individuals and showed a significant decrease in two of the four PPAs of the sources studied, with values between $32 \%$ and $45 \%$ between the years $2007-2008$ and $30 \%$ and $45 \%$ between 2012-2015. In general, the PPAs of the watercourses are degraded, due to the high presence of buildings and the fragmentation of the ciliary vegetation, deteriorating during the analyzed period. Reforestation in PPAs and environmental education with the population are proposed to improve local environmental conditions. Monitoring the quality and quantity of water and extending the historical series considered are ideas for future studies.
\end{abstract}

KEYWORDS: Environment; Quality of Urban Life; Forest Resources.

\section{INTRODUÇÃO}

As primeiras cidades brasileiras se desenvolveram as margens dos rios, um padrão que pode ser atribuído à necessidade humana pelo uso da água e a facilidade na eliminação de dejetos. Atualmente, grande parte da população urbana reside próximo de cursos hídricos importantes, um padrão de localização espacial, incluindo comunidades ribeirinhas, que se apresenta como não favorável à manutenção da sustentabilidade ambiental frente à situação de poluição e escassez de recursos hídricos (CORRÊA; SILVA, 2017).

Com o intuito de conservar o ambiente e os recursos naturais nas propriedades particulares e nas áreas públicas, vários países estabeleceram espaços territoriais protegidos, sendo que no Brasil, Áreas de Preservação Permanente (APPs) foram constituídas como uma das ferramentas de conservação, conforme destacam Vieira et al. (2014). Os mesmos autores afirmam que esses espaços atendem ao chamado "meio ambiente ecologicamente equilibrado", assim, sendo um direito da população de gozar dos serviços ecossistêmicos.

Matiello et al. (2017) conceituam as APPs como sendo "locais protegidos legalmente caracterizados como frágeis e vulneráveis, podendo ser áreas públicas ou privadas, urbanas ou rurais". O novo código florestal brasileiro (Lei n 12.651/12) afirma que as APPs exercem, por exemplo, a "função ambiental de preservar os recursos hídricos, a paisagem, a estabilidade geológica e a biodiversidade, facilitar 0 fluxo gênico de fauna e flora e proteger o solo" (BRASIL, 2012). 
As APPs são importantes por constituírem legalmente uma proteção física e/ou biológica efetiva aos corpos hídricos e seu entorno, sendo que a vegetação presente nesses espaços atua como um obstáculo no escoamento superficial, favorecendo a infiltração e a diminuição do fenômeno da erosão hídrica. Além disso, elas são importantes na busca da qualidade dos recursos hídricos (GUIMARÃES et al., 2015). Silva e Costa (2016) destacam que a criação e manutenção das APPs estão estreitamente ligadas à qualidade de vida, embora a realidade, segundo Hora et al. (2016), consista na ocupação desordenada, pela dificuldade de acesso à terras urbanas e construção de habitações de baixa qualidade que culminem no comprometimento do ambiente e da qualidade de vida das populações locais.

Assim, as APPs vêm sofrendo com a degradação causada pelos agentes antrópicos, provocando consequências como, por exemplo, a mudança de regime fluvial de cursos hídricos (perene para intermitente), interrupção de corredores ecológicos, erosão às margens dos mananciais e danos aos fluxos naturais de sequestro de carbono, sendo este último um indicador quanto ao favorecimento ao aquecimento global (MESQUITA et al., 2010). Hulsmeyer et al. (2015) afirmam que essas áreas também são desprezadas economicamente e que, geralmente, são abandonadas, pelo fato de não serem compreendidas pelo seu potencial de alicerce nas atividades humanas e urbanas com finalidades econômicas.

Os Sistemas de Informação Geográfica (SIG) e Sensoriamento Remoto (SR) são inseridos no grupo das geotecnologias. Essas tecnologias auxiliam na identificação e classificação da cobertura e do uso da terra e podem fornecer subsídios imprescindíveis para planejamento da mitigação e atenuação de impactos ambientais negativos (BARROS et al., 2015). Nesse sentido, existem aplicativos computacionais que podem ser empregados na manipulação de dados geográficos, auxiliando nas mais variadas tomadas de decisões humanas.

A presente pesquisa tem sua importância baseada na carência de estudos aprofundados referentes ao conhecimento do uso da terra e da vegetação remanescente no interior de APPs. Portanto, o objetivo deste trabalho foi estudar os usos atuais e a cobertura florestal remanescente nas áreas de preservação permanente ciliares do município de Mimoso do Sul, estado do Espírito Santo, bem como propor medidas para mitigar e atenuar os impactos ambientais existentes e interpretados.

\section{MATERIAL E MÉTODOS}

A zona urbana do município de Mimoso do Sul está localizada na região sul do Caparaó no estado do Espírito Santo, a uma latitude sul de $21^{\circ} 03^{\prime} 50,40^{\prime \prime}$ e longitude oeste de $41^{\circ} 21^{\prime} 57,60^{\prime \prime}$. A cidade possui um clima quente, com verão seco e inverno chuvoso (INCAPER, 2010). O clima é do tipo Aw segundo a classificação de Köppen. A Figura 1 apresenta a localização do município no estado do Espírito Santo e de sua área urbana consolidada. 


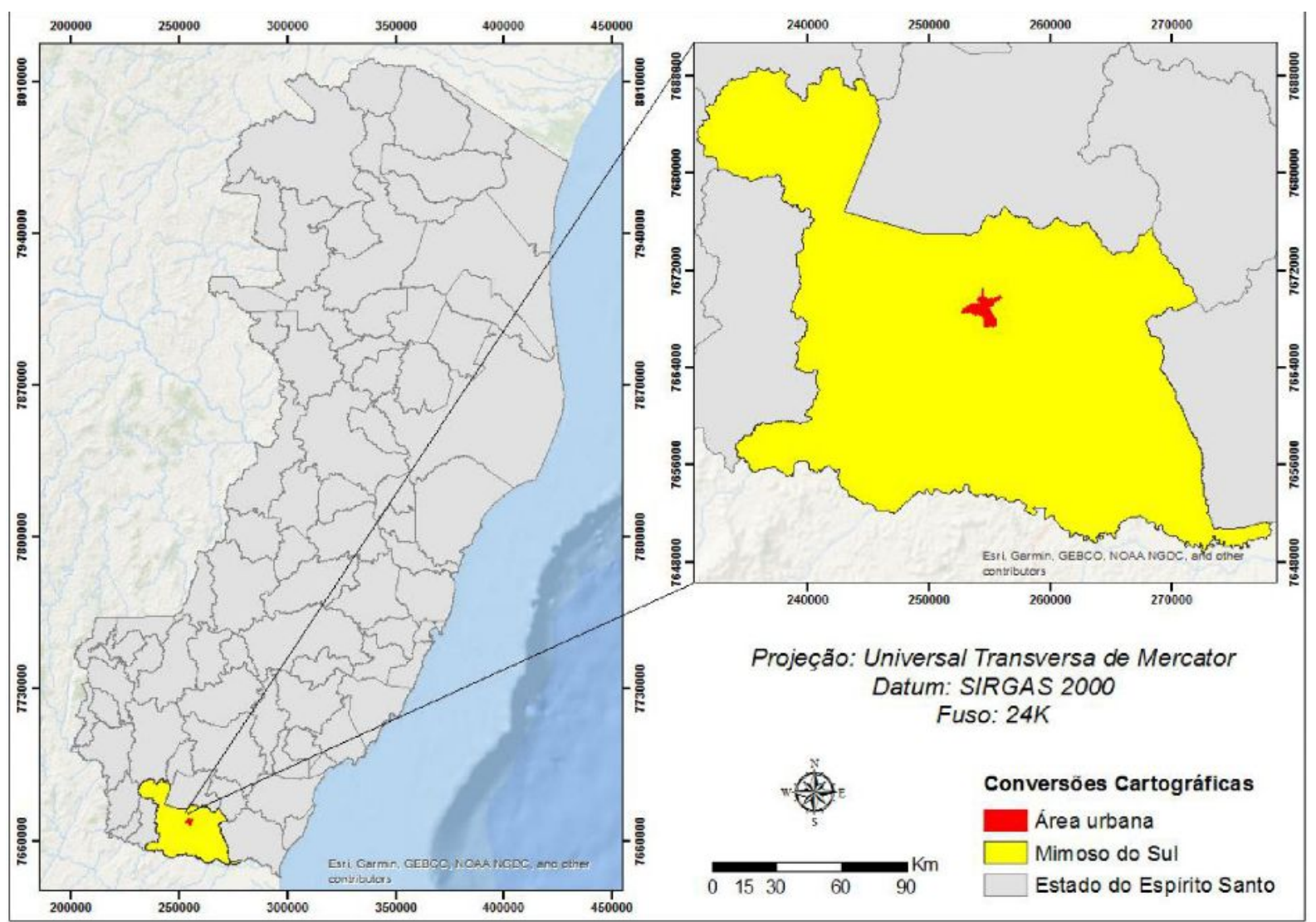

FIGURA 1. Localização do município de Mimoso do Sul e área urbana, Espírito Santo. Fonte: GEOBASES; Instituto Jones dos Santos Neves (2019). Adaptado pelos Autores (2019).

Os procedimentos para a realização desta pesquisa foram executados no aplicativo computacional ArcGis $\AA$ na versão 10.2. Santos et al. (2010) (nas referências consta 2014) afirmam que este programa "fornece ferramentas avançadas para a análise espacial, manipulação de dados e cartografia". Inicialmente, dois arquivos em formato shapefile dos municípios do estado do Espírito Santo e das áreas urbanas dos municípios foram utilizados considerando os limites geográficos dos bairros, sendo oriundo da base de dados do Instituto Jones dos Santos Neves (IJSN).

No ArcGIS®, com auxílio das ferramentas de edição, a área urbana foi extraída somente para o município de Mimoso do Sul para delimitar o local de estudo. Juntamente ao Sistema Integrado de Bases Geoespaciais do Estado do Espírito Santo (GEOBASES), três bases geográficas utilizadas foram adquiridas sendo: um arquivo shapefile referente à cobertura e uso da terra em mapeamentos executados para compor o GEOBASES nos anos de 2007-2008 e 2012-2015; imagens aéreas registradas pelo Sistema durante o mapeamento no quadriênio 2012-2015, com resolução espacial de 0,25 metros.

Ambos os arquivos de cobertura e uso da terra, de acordo com o GEOBASES, estão baseados em escala igual ou superior a 1:25.000 e contêm as informações de todo o território do estado do Espírito Santo. Além dessas bases cartográficas, outro arquivo contendo as feições dos cursos d'água existentes também foi utilizado, extraído do banco de dados do Instituto Brasileiro de Geografia e Estatística (IBGE), e que foi modelado no ano de 2017. 
A base geográfica fornecida pelo IBGE foi adicionada ao layout do ArcGIS, considerando apenas os cursos hídricos que passam pela zona urbana de Mimoso do Sul/ES. Em seguida, as imagens aéreas, com foco apenas na região estudada foram adicionadas, com intuito de ajustar as linhas dos cursos d'água, por meio da criação e edição de um novo arquivo em formato shapefile. Esse procedimento ocorreu através da fotointerpretação das feições em escala 1:900. Por meio das informações contidas na tabela de atributos da shapefile foi possível coletar os dados de cada curso hídrico que atravessa a cidade, bem como medir as larguras (em metros) através da ferramenta measure.

A obtenção da largura de cada corpo hídrico da cidade foi necessária para a posterior delimitação das suas APPs, pois a largura da APP de um curso hídrico varia conforme a largura do respectivo manancial, de acordo com o Código Florestal Brasileiro (BRASIL, 2012). O Quadro 1 mostra os valores considerados para a delimitação das APPs com base nas dimensões de um curso hídrico.

QUADRO 1. Larguras de cursos hídricos e respectivas faixas de APPs delimitadas.

\begin{tabular}{|c|c|}
\hline Largura do curso hídrico & Faixa da APP delimitada \\
\hline Menos de 10 metros & 30 metros \\
\hline De 10 a 50 metros & 50 metros \\
\hline De 50 a 200 metros & 100 metros \\
\hline De 200 a 600 metros & 200 metros \\
\hline Acima de 600 metros & 500 metros \\
\hline
\end{tabular}

Fonte: Adaptado de Brasil (2012).

A delimitação das APPs no programa foi feita através da ferramenta buffer. Posteriormente, foram editados os arquivos de cobertura e uso da terra para os mapeamentos dos anos de 2007-2008 e 2012-2015, considerando apenas as APPs da região em estudo. Para cada mapeamento, por meio da tabela de atributos e dos recursos de estimativa de áreas, foram determinadas e quantificadas as classes de cobertura e uso da terra das APPs, estudando-as para cada mapeamento e curso hídrico analisado. A representação dos dados quantificados foi feita em percentagem (\%) e em metros quadrados $\left(\mathrm{m}^{2}\right)$.

Com intuito de verificar maior precisão na distribuição dos fragmentos de vegetação, por meio da fotointerpretação das feições na escala 1:900, foram determinadas as porcentagens dessa vegetação nas APPs de cada curso hídrico considerado. Além disso, dois mapas finais foram gerados, com intuito de analisar a distribuição espaço-temporal da vegetação arbórea remanescente.

\section{RESULTADOS E DISCUSSÃO}

O Quadro 2 e a Figura 2 demonstram, respectivamente, as dimensões da largura das APPs de cada curso hídrico que passa pela cidade e a representação desses mananciais em um mapa temático.

QUADRO 2. Tamanhos das faixas das APPs, delimitadas para cada curso hídrico estudado na zona urbana de Mimoso do Sul (ES).

\begin{tabular}{|c|c|}
\hline Nomenclatura do curso hídrico & Faixa da APP \\
\hline Córrego Belo Monte & 30 metros \\
\hline Córrego da Serra & 30 metros \\
\hline Córrego Santa Marta & 30 metros \\
\hline Rio Muqui do Sul & 50 metros \\
\hline
\end{tabular}

AGRARIAN ACADEMY, Centro Científico Conhecer - Goiânia, v.6, n.11; p. 331 


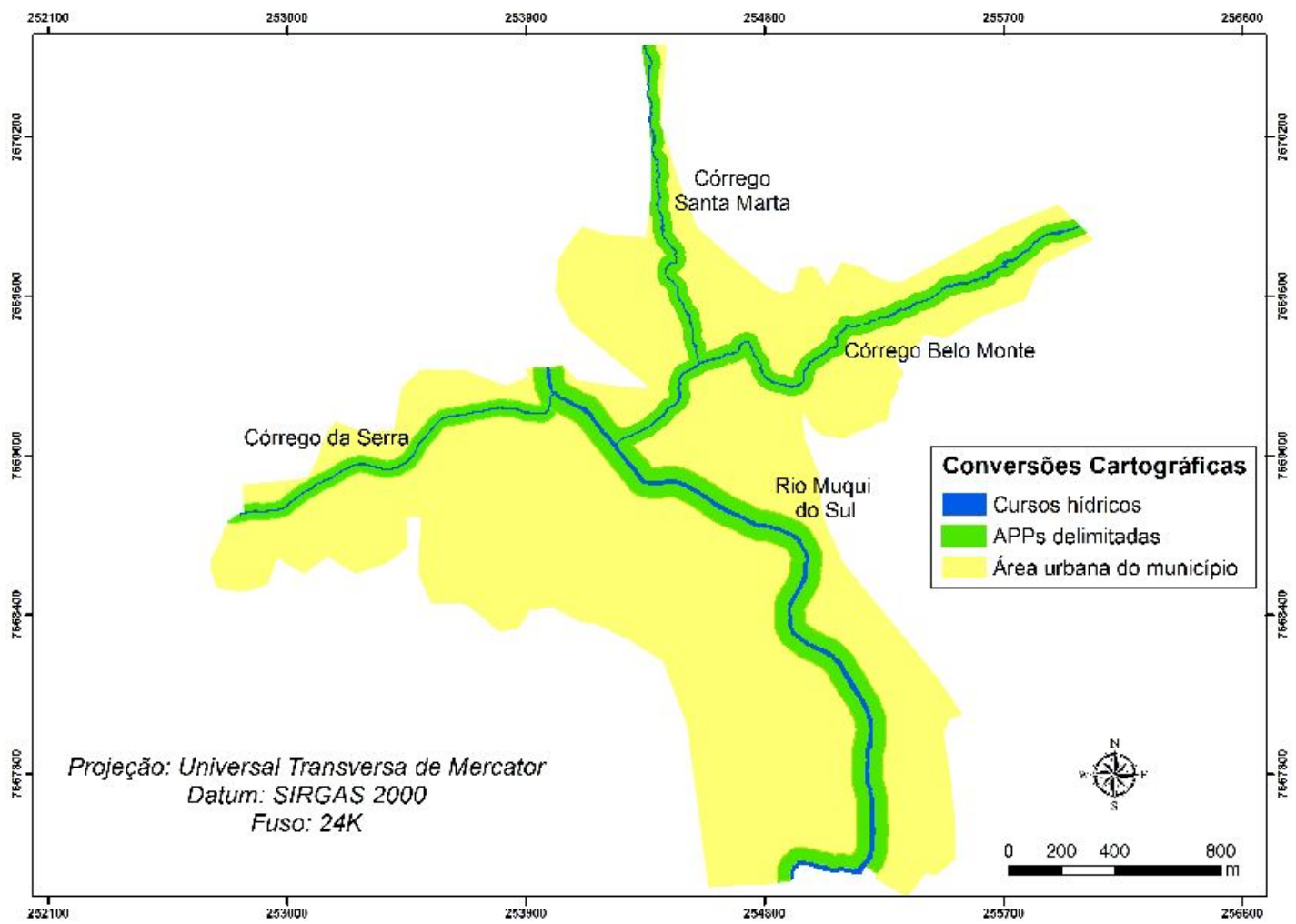

FIGURA 2. Distribuição espacial dos cursos hídricos e suas respectivas APPs. Fonte: GEOBASES; Instituto Jones dos Santos Neves (2019). Adaptado pelos Autores (2019).

Os resultados da análise do mapeamento apontam que a cidade de Mimoso do Sul é cortada por quatro cursos hídricos, sendo que o principal é o rio Muqui do Sul que, por sua vez, apresenta maiores dimensões, possuindo, então, maior valor de largura da sua faixa de APP.

A área total da zona urbana do município corresponde a 352,2 ha, sendo que as APPs abrangem 61,2 ha, ou seja, representam em torno de $17,4 \%$ da área total urbana. Número superior à APPs de outras cidades como, por exemplo, de Indaiatuba/SP, em que Araújo e Matias (2017) observaram que esses locais contêm apenas $10,8 \%$ de APPs remanescente na área urbanizada.

As Tabelas 1 e 2 apresentam o percentual e as classes da cobertura e uso da terra para os cursos hídricos referentes ao mapeamento do GEOBASES dos anos 2007-2008 e 2012-2015, respectivamente. 
TABELA 1. Percentual de classes de cobertura e uso da terra no interior de APPs de cursos hídricos em mapeamento realizado no período entre 20072008

\begin{tabular}{|c|c|c|c|c|}
\hline CLASSES & $\begin{array}{c}\text { CÓRREGO } \\
\text { BELO } \\
\text { MONTE }\end{array}$ & $\begin{array}{l}\text { CÓRREGO } \\
\text { DA SERRA }\end{array}$ & $\begin{array}{c}\text { CÓRREGO } \\
\text { SANTA } \\
\text { MARTA }\end{array}$ & $\begin{array}{l}\text { RIO MUQUI } \\
\text { DO SUL }\end{array}$ \\
\hline Área edificada & $55,854 \%$ & $79,738 \%$ & $40,882 \%$ & $70,941 \%$ \\
\hline Cultivo agrícola - café & $0,634 \%$ & $0 \%$ & $0 \%$ & $0 \%$ \\
\hline $\begin{array}{c}\text { Outros cultivos } \\
\text { permanentes }\end{array}$ & $3,954 \%$ & $0 \%$ & $0 \%$ & $0 \%$ \\
\hline Outros cultivos temporários & $7,690 \%$ & $0 \%$ & $0 \%$ & $0 \%$ \\
\hline $\begin{array}{l}\text { Floresta nativa em estágio } \\
\text { inicial de reqeneracão }\end{array}$ & $3,972 \%$ & $0 \%$ & $0 \%$ & $0 \%$ \\
\hline Macega & $0,222 \%$ & $2,542 \%$ & $0 \%$ & $2,542 \%$ \\
\hline Pastagem & $6,421 \%$ & $8,216 \%$ & $39,817 \%$ & $8,216 \%$ \\
\hline Outras classes & $21,253 \%$ & $9,505 \%$ & $19,302 \%$ & $9,505 \%$ \\
\hline
\end{tabular}

TABELA 2. Percentual de classes de cobertura e uso da terra no interior de APPs de cursos hídricos em mapeamento realizado no período entre 20122015

\begin{tabular}{ccccc}
\hline CLASSES & $\begin{array}{c}\text { CÓRREGO } \\
\text { BELO } \\
\text { MONTE }\end{array}$ & $\begin{array}{c}\text { CÓRREGO } \\
\text { DA SERRA }\end{array}$ & $\begin{array}{c}\text { CÓRREGO } \\
\text { SANTA } \\
\text { MARTA }\end{array}$ & $\begin{array}{c}\text { RIO MUQUI } \\
\text { DO SUL }\end{array}$ \\
\hline $\begin{array}{c}\text { Área edificada } \\
\text { Cultivo agrícola - café }\end{array}$ & $\begin{array}{c}\text { C1,129\% } \\
1,312 \%\end{array}$ & $80,097 \%$ & $42,810 \%$ & $67,881 \%$ \\
Outros cultivos permanentes & $0 \%$ & $0 \%$ & $10,466 \%$ & $0 \%$ \\
Outros cultivos temporários & $7,69 \%$ & $0 \%$ & $0 \%$ & $0,164 \%$ \\
$\begin{array}{c}\text { Floresta nativa em estágio } \\
\text { inicial de regeneração }\end{array}$ & $0 \%$ & $0 \%$ & $0 \%$ & $0 \%$ \\
Macega & $1,463 \%$ & $1,427 \%$ & $19,088 \%$ & $0 \%$ \\
Pastagem & $2,655 \%$ & $0 \%$ & $8,335 \%$ & $0,797 \%$ \\
Outras classes & $25,751 \%$ & $18,476 \%$ & $19,302 \%$ & $30,004 \%$ \\
\hline
\end{tabular}

Através do mapeamento do GEOBASES, não foi possível quantificar fragmentos de vegetação arbórea, sendo que tal atividade pode ser realizada quando há fragmentos de vegetação com elementos arbóreos onde as copas se tocam, apresentando padrões mais contínuos de cobertura vegetal. Contudo, para as outras classes de cobertura e uso da terra, a identificação e quantificação foram feitas com sucesso.

Com relação às áreas edificadas, apenas a APP do rio Muqui do Sul apresentou uma pequena redução, que foi em torno de $3 \%$, ao passo que a área construída da APP do córrego Belo Monte aumentou em pouco mais de $5 \%$. A APP do córrego da Serra apresenta mais de $80 \%$ de sua área ocupada por edificações. Beltrame e Taveira (2016) afirmam que, no território brasileiro, as áreas urbanas são alvo de várias formas de ocupações irregulares como, por exemplo, favelas e loteamentos irregulares ou clandestinos, sem a devida preocupação com a qualidade ambiental local. Além dos problemas supracitados, destaca-se também o consequente aumento da impermeabilidade do solo.

Todos os cursos hídricos apresentaram redução nas áreas de pastagem, sendo que a maior redução foi vista na APP do córrego Santa Marta. Isso se deve ao aumento das áreas de macega (regeneração florestal) e cafezais, que AGRARIAN ACADEMY, Centro Científico Conhecer - Goiânia, v.6, n.11; p. 333 
apresentaram grande crescimento no seu entorno. Exceto no córrego Santa Marta, na vizinhança dos demais cursos hídricos, as áreas de pastagem e macega apresentaram mudanças de pouca significância no mapeamento 2012-2015.

De acordo com Pessi et al. (2017), as pastagens em APP provocam perda da qualidade ambiental local, pois, desprovidas de vegetação e com o pisoteio do gado, a terra dessas áreas se torna frágil e vulnerável à erosão. Dessa forma, podem comprometer a qualidade e quantidade de água dos cursos hídricos próximos, afetando, também, as populações que residem em seu entorno. No entanto, para os cursos hídricos da zona urbana de Mimoso do Sul (ES), esse fato vem sendo minimizado com a diminuição das áreas de pastagem, constituindo, assim, um fator positivo para melhorar a qualidade ambiental dessas áreas em longo prazo no tocante a redução dessa classe de uso da terra.

Macega é uma forma de vegetação alterada, em que predominam indivíduos do porte herbáceo e arbustivo e, raramente, arbóreo (GOVERNO DO ESTADO DO ESPÍRITO SANTO, 1997). Em Mimoso do Sul, o aumento de áreas de macega, sobretudo no córrego Santa Marta, indica que as APPs não estão sendo devidamente aproveitadas para atividades de recuperação ambiental, evidenciando, assim, um problema quanto ao manejo e planejamento do uso das terras desses locais.

Em termos ambientais e com base nas classes identificadas e quantificadas, a APP do rio Muqui do Sul foi a que apresentou mudanças na sua qualidade ambiental, por meio da diminuição drástica dos índices de pastagem e por não haver grande aumento no valor de área construída. Contudo, as classes não identificadas pelo mapeamento apresentaram um alto número, o que limitou uma caracterização mais precisa do uso de solo nessa área com base na metodologia considerada.

As Figuras 3 e 4 mostram os resultados do mapeamento da vegetação arbórea feito pela fotointerpretação das feições de cobertura florestal, referente às imagens aéreas dos anos 2007-2008 e 2012-2015, respectivamente.

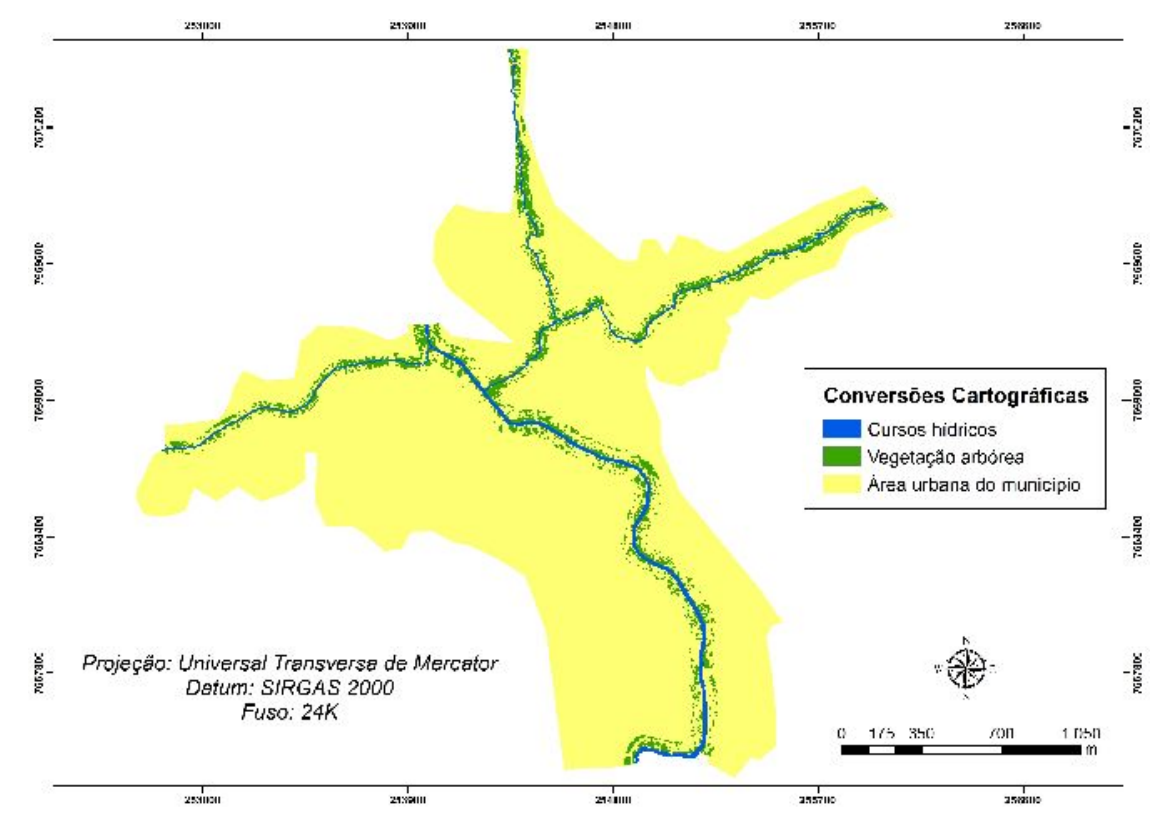

FIGURA 3. Distribuição espacial da vegetação arbórea das APPs na fotointerpretação das imagens dos anos 2007-2008.

Fonte: GEOBASES; Instituto Jones dos Santos Neves (2019). Adaptado pelos Autores (2019). 


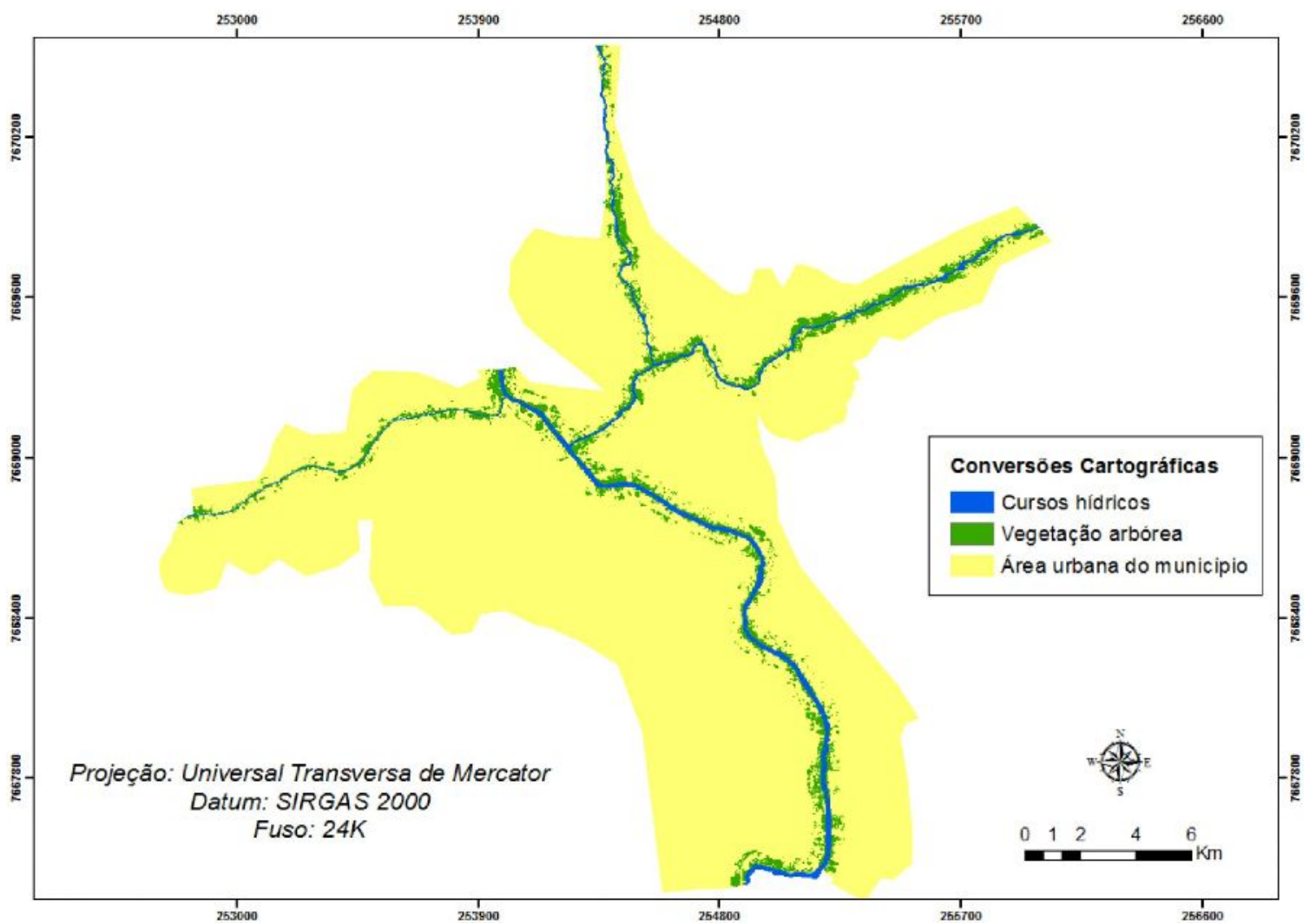

FIGURA 4. Distribuição espacial da vegetação arbórea das APPs referente à fotointerpretação das imagens dos anos 2012-2015.

Fonte: GEOBASES; Instituto Jones dos Santos Neves (2019). Adaptado pelos Autores (2019).

A vegetação arbórea esteve muito fragmentada ao longo dos trechos de APP, sobretudo na mata ciliar do córrego da Serra, que apresentou uma nítida dinâmica de redução. Apenas em trechos dos córregos Belo Monte e Santa Marta, há maiores e aglomerados fragmentos de mata ciliar. A APP do rio Muqui do Sul, apesar de possuir 50 metros de largura e ser a foz dos demais cursos hídricos da cidade, não se encontra devidamente preservada, apesar de ter havido um decréscimo de áreas construídas e um aparecimento de áreas em estágio inicial de regeneração. Entendido como uma área de vegetação natural que foi bloqueada por ação natural ou antrópica, um fragmento florestal isolado provoca diminuição do número e fluxo de espécies e o preocupante isolamento espacial de indivíduos da fauna e flora (PERONDI et al., 2018), sendo um motivo de preocupação para as APPs dos cursos hídricos estudados.

A Tabela 3 mostra a quantificação das áreas, em porcentagem, de vegetação arbórea para cada curso hídrico nos mapeamentos dos anos 2007-2008 e 20122015.

TABELA 3. Porcentagens de área de vegetação arbórea para cada curso hídrico extraído por fotointerpretação nos mapeamentos realizados.

\begin{tabular}{ccc}
\hline CURSOS HíDRICOS & $\begin{array}{c}\text { MAPEAMENTO } \\
\mathbf{2 0 0 7 - 2 0 0 8}\end{array}$ & $\begin{array}{c}\text { MAPEAMENTO } \\
\mathbf{2 0 1 2 - 2 0 1 5}\end{array}$ \\
\hline Córrego Belo Monte & $44,5 \%$ & $44,5 \%$ \\
Córrego da Serra & $45,9 \%$ & $30,0 \%$ \\
Córrego Santa Marta & $49,4 \%$ & $37,8 \%$ \\
Rio Muqui do Sul & $32,6 \%$ & $30,6 \%$ \\
\hline
\end{tabular}


Em três cursos hídricos houve redução da vegetação arbórea fragmentada, ao passo que apenas a APP do córrego Belo Monte apresentou estabilidade nas áreas arborizadas. A maior redução ocorreu no córrego da Serra, o que evidencia maiores necessidades das ações de recuperação ou restauração da APP desse curso hídrico. Tessaro (2016) afirma que a mata ciliar é de extrema importância para a fauna e flora, além de ser favorecida pelas condições de água e nutrientes para sua formação nas margens dos mananciais.

Fiorese (2018) em estudos acerca da cobertura e uso das terras da APP do rio Castelo, na zona urbana do município de Conceição do Castelo/ES, constatou que houve uma redução em torno de $6 \%$ da vegetação arbórea no mesmo período considerado. Preocupação também evidente nas APPs dos cursos hídricos analisado na presente pesquisa em Mimoso do Sul.

Os prejuízos causados pelo uso inadequado das APPs (redução da vegetação ciliar nativa) refletem, por exemplo, no clima e na perda da qualidade ambiental, além da consequente deterioração do bem-estar da população (MATIELLO et al., 2017). Diante desse cenário, Souza et al. (2014) afirmam que a recuperação da APP aumentaria a área e proximidade dos fragmentos florestais, trazendo uma série de benefícios, tanto ao homem, quanto à natureza.

De maneira geral, as APPs estudadas sofreram certa degradação no período analisado. Afirmação também constatada em trabalhos semelhantes, como o de Lacorte e Almeida (2015) que, em estudos sobre a bacia hidrográfica do córrego Liso em Uberlândia (MG), constataram que dois quintos da APP local se encontram ocupadas por pastagem ou área edificada. Bilac e Alves (2014) afirmam que, o avanço da degradação em APPs atingirá níveis mais alarmantes caso continue faltando planejamento e articulação político-social no tocante aos problemas socioambientais e planejamento territorial.

\section{CONCLUSÃO}

As Áreas de Preservação Permanente dos cursos hídricos da cidade de Mimoso do Sul (ES), de modo geral, encontram-se degradadas, sobretudo no que tange à ocupação por construções e edificações. A vegetação ciliar está com alto grau de fragmentação e apresentou um decréscimo na maior parte das APPs de cursos hídricos locais, afetando possivelmente, não somente a fauna e flora, como também a qualidade de vida da população urbana desta cidade. Portanto, a realização de medidas mitigatórias como recuperação da mata ciliar, fiscalização e planejamento no gerenciamento do uso das terras locais, bem como promoção da educação ambiental nas escolas e com a população local, são ações imprescindíveis para modificar o padrão deletério atual, bem como proporcionar melhorias na qualidade de vida da cidade.

Estudos futuros poderiam ser feitos com base na ampliação da série histórica analisada sobre a evolução da cobertura da terra nas APPs estudadas, embora a análise dos resultados obtidos já demonstre de fato a necessidade de ações imediatas e continuadas para recuperação e amplificação do uso consciente dos recursos naturais locais. Finalmente, uma preocupação paralela se refere à necessidade de implementar o monitoramento da quantidade e qualidade de água nos mananciais, um trabalho que não tem sido feito pelas agências do governo em parceria com as universidades e comunidades locais na quase totalidade dos rios brasileiros. 


\section{REFERÊNCIAS}

ARAÚJO, L. de S.; MATIAS, L. F. Áreas de preservação permanente no município de Indaiatuba (SP). Revista Geografar, Curitiba, v. 12, n. 2, p. 196-214, jul./dez. 2017. Disponível em: <https://revistas.ufpr.br/geografar/article/view/48480/34691>. doi: http://dx.doi.org/10.5380/geografar.v12i2.48480

BARROS, A. C. de.; SILVA, T. J. da.; COSTA, D. de M.; GARCIA, Y. M. Conflitos em áreas de preservação permanente na microbacia do córrego da Água Amarela, Itaberá/SP. Revista Meio Ambiente e Sustentabilidade, Curitiba, v. 9, n. 4, p. 156 168, 2015. Disponível em: <https://www.uninter.com/revistameioambiente/index.php/ meioAmbiente/article/view/372>. doi: http://dx.doi.org/10.22292/mas.v9i4.372

BELTRAME, F. M.; TAVEIRA, A. do V. A. As áreas urbanas consolidadas e a área de preservação permanente: uma análise reflexiva. Revista Faz Ciência, v. 18, n. 27, p. 76-92, jan./jun. 2016. Disponível em: <http://e-revista.unioeste.br/index.php/faz ciencia/article/view/15850/10768>.

BILAC, R. P. R.; ALVES, A. de M. Crescimento urbano nas Áreas de Preservação Permanente (APPs): um estudo de caso do leito do rio Apodi/Mossoróna zona urbana de Pau dos Ferros-RN. Revista Geotemas, Pau dos Ferros, v. 4, n. 2, p. 7995, jul./dez. 2014. Disponível em: <http://periodicos.uern.br/index.php/geotemas/artic le/view/1261/716>.

BRASIL. Lei $n^{\circ} 12.651$, de 25 de maio de 2012. Dispõe sobre a vegetação nativa e dá outras providências. Diário Oficial da União, Brasília, DF, 28 mai. 2012.

CORRÊA, C.; SILVA, A. Considerações sobre a redução/ampliação da dimensão de áreas de preservação permanente de faixa marginal de curso d'água em três áreas no Rio Paraíba do Sul - RJ, Brasil. Revista de Geografia e Ordenamento do Território, Porto, n. 11, p. 125-147, 2017. Disponível em: <http://www.scielo.mec.pt/ scielo.php?script=sci_arttext\&pid=S2182-12672017000100007>. doi: dx.doi.org/10.17127/got/2017.11.006

FIORESE, C. H. U. Comportamento temporal do uso de solo das Áreas de Preservação Permanente do rio Castelo - trecho urbano do município de Conceição do Castelo, ES. In: CONGRESSO BRASILEIRO DE REFLORESTAMENTO AMBIENTAL, 5., 2018, Vitória. Anais... Vitória: CEDAGRO, 2018.

GEOBASES. Imagens do mapeamento ES 2012-2015 disponíveis para download. Disponível em: <https://geobases.es.gov.br/novas-imagens-map-es2012-2015-sem-ecw>.

GOVERNO DO ESTADO DO ESPÍRITO SANTO. Decreto $n^{\circ} 4.124-\mathrm{N}$, de 12 de junho de 1997. Aprova o regulamento sobre a política florestal do estado do Espírito Santo. 1997.

GUIMARÃES, B. B.; GUIMARÃES, R. B.; LEAL, A. C. Código florestal brasileiro: análise do conceito de Área de Preservação Permanente e sua aplicação na bacia hidrográfica do Córrego São Pedro - Anhumas, São Paulo. Boletim Campineiro de 
Geografia, Campinas, v. 5, n. 1, p. 157-173, 2015. Disponível em: <http://agbcampinas.com.br/bcg/index.php/boletim-campineiro/article/view/192/127>.

HORA, K. E. R.; RIBEIRO, J. P.; OLIVEIRA, V. T.; MARQUES, P. H. G. Caracterização das ocupações em áreas de preservação permanente às margens do ribeirão Anicuns e do córrego Botafogo na cidade de Goiânia. Cadernos do Núcleo de Análises Urbanas, v. 9, n. 1, p. 99-115, 2016. Disponível em: $<$ https://periodicos.furg.br/cnau/article/view/6582/4668>.

HULSMEYER, A. F.; FRANÇOSO, B. E.; PANISSA, A. E. O. As áreas de preservação permanente como espaços livres urbanos: um estudo de caso em Umuarama-PR. Revista Akrópolis, Umuarama, v. 23, n. 2, p. 191-205, jul./dez. 2015. Disponível em: <http://revistas.unipar.br/index.php/akropolis/article/viewFile/ 5766/3269>. doi: https://doi.org/10.25110/akr\%C3\%B3polis.v23i2.5766

INCAPER. Programa de assistência técnica e extensão rural PROATER 2011 2013: Mimoso do Sul. Disponível em: <https://incaper.es.gov.br/media/incaper/proat er/municipios/Caparao/Mimoso.pdf>. Link não ativo.

INSTITUTO JONES DOS SANTOS NEVES. Shapefiles. 2019. Disponível em: $<$ http://www.ijsn.es.gov.br/mapas/>.

LACORTE, I. M.; ALMEIDA, M. R. R. e. Impactos ambientais em áreas de preservação permanente de centros urbanos: o caso da bacia do córrego Liso em Uberlândia. Revista Enciclopédia Biosfera, Goiânia, v. 11, n. 22, p. 1464-1475, 2015. Disponível em: <http://www.conhecer.org.br/enciclop/2015c/agrarias/impactos\%20ambientais.pdf>. doi: http://dx.doi.org/10.18677/Enciclopedia_Biosfera_2015_175

MATIELLO, S.; CERRI, F.; PAGANI, C. P.; LIMA, J. S. O uso do geoprocessamento para delimitação e análise das áreas de preservação permanente de um córrego em nova Mutum Paraná- RO. Revista Presença Geográfica, v. 6, n. 1, p. 40-50, 2017. Disponível em:<http://www.periodicos.unir.br/index.php/RPGeo/article/view/2622>.

MESQUITA, R. A. S.; BRITO, M. R.; MARINHO, A. A.; MURAISHI, C. T. A importância das áreas de preservação permanente (APPs). Disponível em: $<$ http://www.catolica-to.edu.br/portal/portal/downloads/docs_gestaoambiental/projeto s2010-1/3-periodo/A_importancia_das_areas_de_preservacao_permanete.pdf $>$. Completar informações da publicação. (editora, Volume, Numero, ano).

PERONDI, C.; ROSA, K. K. da.; MURARA, P. G. dos S. Fragmentação florestal e mudanças na distribuição biogeográfica na microbacia do rio Mão Curta, Sananduva, RS. Revista Eletrônica Para Onde!?, Porto Alegre, v. 9, n. 1, p. 51-74, jan./jul. 2018. Disponível em: <https://seer.ufrgs.br/paraonde/article/viewFile/64896/48516>.

PESSI, D.; REMPEL, C.; HAETINGER, C. Diagnóstico do uso da terra em Áreas de Preservação Permanente de pequenas propriedades rurais produtoras de leite no Vale do Taquari/RS, Brasil. Revista Espacios, v. 38, n. 2, 2017. Disponível em: <http://www.revistaespacios.com/a17v38n22/a17v38n21p07.pdf>. 
SANTOS, A. R. dos.; EUGÊNIO, F. C.; RIBEIRO, C. A. A. S.; SOARES, V. P.; MOREIRA, M. A. et al. ArcGIS 10.2.2 passo a passo: elaborando meu primeiro mapeamento. Alegre: CAUFES, 2014. 53 p.

SILVA, F. P. de S.; COSTA, B. S. Construção em área de preservação permanente e desrespeito a princípios ambientais na sociedade de risco: apontamentos ao recurso especial $n^{\circ}$ 1.245.149/MS. Argumenta Journal Law, Jacarezinho, n. 23, p. 233-251, 2016. Disponível em: <http://seer.uenp.edu.br/index.php/argumenta/article/ viewFile/632/pdf_104>.

SOUZA, C. G.; ZANELLA, L.; BORÉM, R. A. T.; CARVALHO, L. M. T. de.; ALVES, H. M. R. et al. Análise da fragmentação florestal da área de proteção ambiental Coqueiral, Coqueiral - MG. Revista Ciência Florestal, Santa Maria, v. 24, n. 3, p. 631-644, jul./set. 2014. Disponível em: <http://www.scielo.br/scielo.php?pid=S198050982014000300631\&script=sci_abstract\&tlng=pt>. doi: dx.doi.org/10.1590/1980509820142403011

TESSARO, T. P. Recuperação de área de mata ciliar degradada parcialmente recuperada no município de Ouro, Santa Catarina. Revista Unoesc \& Ciência, Joaçaba, v. 7, n. 2, p. 215-220, jul./dez. 2016. Disponível em: <https://editora.unoesc.edu.br/index.php/acbs/article/download/10933/pdf>.

VIEIRA, E. G.; GONÇALVES, D. O.; BOEING, J. Áreas de preservação permanente: peculiaridades do tema no Brasil, Estados Unidos, Portugal e Espanha. Revista Lex Humana, Petrópolis, v. 6, n. 1, p. 44-69, 2014. Disponível em: <http://seer.ucp.br/seer/index.php/LexHumana/article/viewFile/540/305>. Acesso em: 19 dez. 2018. doi: http://dx.doi.org/10.14195/2175-0947_6-1_4 